\title{
Induced pluripotent stem cells derived from the developing striatum as a potential donor source for cell replacement therapy for Huntington disease
}

\author{
Narawadee Choompoo ${ }^{1,2, \dagger}$, Oliver J.M. Bartley ${ }^{1, \dagger}$, Sophie V. Precious ${ }^{1, \dagger}$, Ngoc-nga Vinh ${ }^{1}$, \\ Christian Schnell ${ }^{1}$, Ana Garcia ${ }^{1}$, Victoria H. Roberton ${ }^{1}$, Nigel M. Williams ${ }^{4}$, Paul J. Kemp ${ }^{1}$, \\ Claire M. Kelly ${ }^{1,3, \ddagger}$, Anne E. Rosser ${ }^{1,4,5, \ddagger, *}$ \\ ${ }^{1}$ Brain Repair Group, School of Biosciences, Cardiff University, Cardiff, UK \\ ${ }^{2}$ Department of Anatomy, Faculty of Medical Science, Naresuan University, Phisanulok, Thailand \\ ${ }^{3}$ Cardiff School of Sport and Health Sciences, Cardiff Metropolitan University, Cardiff, UK \\ ${ }^{4}$ MRC Centre for Neuropsychiatric Genetics and Genomics, School of Medicine, Cardiff University, Cardiff, UK \\ ${ }^{5}$ Wales Brain Repair and Intracranial Neurotherapeutics Unit, School of Medicine, Cardiff University, Cardiff, UK
}

\section{A R T I C L E I N F O}

\section{Article History:}

Received 11 May 2020

Accepted 16 June 2020

Key Words:

cell therapy

epigenetic memory

fetal tissue

Huntington disease

iPSC

striatal differentiation

\begin{abstract}
A B S T R A C T
Background : Cell replacement therapy (CRT) for Huntington disease (HD) requires a source of striatal (STR) progenitors capable of restoring the function lost due to STR degeneration. Authentic STR progenitors can be collected from the fetal putative striatum, or whole ganglionic eminence (WGE), but these tissues remain impractical for widespread clinical application, and alternative donor sources are required. Here we begin exploring the possibility that induced pluripotent stem cells (iPSC) derived from WGE may retain an epigenetic memory of their tissue of origin, which could enhance their ability to differentiate into STR cells. Results: We generate four iPSC lines from human WGE (hWGE) and establish that they have a capacity similar to human embryonic stem cells with regard to their ability to differentiate toward an STR phenotype, as measured by expression and demethylation of key STR genes, while maintaining an overall different methylome. Finally, we demonstrate that these STR-differentiated hWGE iPSCS share characteristics with hWGE (i.e., authentic STR tissues) both in vitro and following transplantation into an HD model. Overall, iPSCs derived from human WGE show promise as a donor source for CRT for HD.
\end{abstract}

(c) 2020 International Society for Cell \& Gene Therapy. This is an open access article under the CC BY license (http://creativecommons.org/licenses/by/4.0/)

\section{Introduction}

Huntington disease (HD) is a neurodegenerative condition associated with motor, cognitive and psychiatric symptoms [1]. One of the earliest and most prominent neuropathological features is the gradual and progressive loss of striatal (STR) medium spiny neurons (MSNs), with further atrophy occurring in other brain regions as the disease progresses [2,3]. There is currently no cure, and HD patients typically die within $15-30$ years of disease onset. Cell replacement therapy (CRT) is a potential medical intervention for HD, aiming to restore function by replenishing the degenerating MSN population. Intra-STR allografts of MSN progenitors derived from primary fetal whole ganglionic eminence (WGE), the primordial striatum, have

\footnotetext{
* Correspondence: Anne E. Rosser, PhD, FRCP, Brain Repair Group, School of Biosciences, Cardiff University, Cardiff, UK, CF10 3AX

E-mail addresses: rosserae@cf.ac.uk, bartleyoj@cardiff.ac.uk (A.E. Rosser).

$\dagger$ These authors contributed equally to this work

$\ddagger$ These authors contributed equally to this work.
}

been shown to express DARPP-32 (PPP1R1B), the principal marker of MSNs, and bring about motor and cognitive functional recovery in HD rat models. Similarly, expression of DARPP-32 donor-derived cells, along with functional improvements, has been observed in xenografts of human WGE (hWGE) in the HD rat striatum [4]. CRT clinical trials have provided evidence of safety and feasibility of intra-STR transplantation of primary hWGE in HD patients. Furthermore, there is some evidence of long-term graft survival and functional benefits to transplant recipients $[5,6]$. As such, primary hWGE tissues are currently considered the gold standard donor source for CRT in HD, but they also present a plethora of logistical, quality control and ethical challenges for clinical translation. Hence, there is interest in identifying renewable MSN progenitor sources for clinical application [7].

Human pluripotent stem cells (hPSCs), principally human embryonic stem cells (hESCs) and human induced PSCs (iPSCs), are an appropriate alternative donor source, as they are renewable, accessible for quality control and theoretically capable of differentiating toward an STR fate [4]. There is evidence that iPSCs inherit some 
epigenetic features associated with the cells from which they were derived, which results in some retained phenotypic features $[8,9]$. Specific examples include iPSCs derived from insulin-producing $\beta$ cells [10] and hematopoietic [11], cardiac [12], ocular [13] and neural [14] tissues. Critically, iPSCs derived from forebrain progenitors have been demonstrated to possess an enriched gene expression profile typical of their region of origin, which is reported to enhance their survival following transplantation into the rodent forebrain [15]. Based on the notion that iPSCs can retain an epigenetic profile characteristic of their tissue of origin, we asked whether iPSCs derived from hWGE would be epigenetically primed to differentiate toward STR fates. Specifically, we sought to broadly establish how hWGEderived iPSCs compared with hWGE in terms of key gene expression markers, epigenetic signatures and engraftment potential.

\section{Methods}

\section{Ethics and approval}

Human fetal tissue was obtained via SWIFT-RTB with full ethical approval and under the UK Human Tissue Authority research license held by Cardiff University (No. 12422). All procedures with animals were performed in full compliance with the UK Animals Act 1986 (Scientific Procedures) and approved by local ethical review.

\section{Human WGE iPSC generation, culture and validation}

Human WGE iPSC generation is described in Supplementary Materials and Methods. In brief, hWGE was dissected and dissociated as previously described [16]. Human WGE iPSCs were generated by transfecting hWGE with piggyBac transposons and transposase (Sanger Institute). Pluripotent-like colonies were identified microscopically, manually picked and then cultured separately as clones, following which integrated transposons were removed [17]. Human PSCs were maintained on irradiated mouse embryonic fibroblasts in ReproStem medium (ReproCell) supplemented with basic fibroblast growth factor (bFGF) $(25 \mu \mathrm{g} / 500 \mathrm{~mL})$. For spontaneous differentiation, bFGF was removed from culture for 14-21 days. For teratoma formation, hWGE iPSCs $\left(1 \times 10^{6}\right)$ were injected subcutaneously into immunodeficient mice, which were culled at 8 weeks and the tumors dissected.

\section{STR differentiation}

\section{Base media}

Three types of media were used for differentiation: (i) KnockOut (K/O) medium, as DMEMF/12, KnockOut Serum Replacement (1:100), L-glutamine (200 mM), non-essential amino acid (1:100) and penicillin-streptomycin (1:100) (all Gibco), and $\beta$-mercaptoethanol (50 $\mathrm{mM}$; Sigma);

(ii) N2B27 medium, as Advanced DMEM/F12: Neurobasal (1:1), N2 (1:150) and B27 (+RA, 1:150) (all Gibco);

and (iii) N2B27-RA medium, as N2B27 without RA.

\section{Protocol}

On day 2, hWGE iPSCs were passaged into small clumps and transferred to ReproStem without bFGF to form embryoid bodies (EBs). On day 0, EBs were transferred to K/O medium with SB431542 $(10 \mu \mathrm{M})$, dorsomorphin $(200 \mu \mathrm{M})$ (Tocris) and Noggin $(500 \mu \mathrm{g} / \mathrm{mL}$; R\&D). On day 5, EBs were transferred to N2B27 medium with $S H H$ $(100 \mathrm{ng} / \mathrm{mL})$ and $D K K 1(100 \mathrm{ng} / \mathrm{mL})$ (both R\&D). On day 10, EBs were plated on Matrigel (Corning) coated plates in N2B27 medium $+\mathrm{SHH}$ $+D K K 1$. On day 16, cells were dissociated with Accutase (Sigma), plated on poly-l-lysine/laminin-coated six-well plates $\left(1 \times 10^{6}\right.$ cells/ well) and cultured in N2B27-RA medium + SHH+DKK1. On day 20, Activin A (25 ng/mL; R\&D) was added to N2B27-RA. On day 22, cells were passaged as single cells onto poly-l-lysine/laminin-coated sixwell plates $\left(1 \times 10^{6}\right.$ cells/well). From day 30 onward, medium was changed to N2B27 with brain-derived neurotrophic factor (100 ng/ $\mathrm{mL}$ ) and glial cell-derived neurotrophic factor $(10 \mathrm{ng} / \mathrm{mL}$ ) (both PeproTech) as well as ascorbic acid $(200 \mu \mathrm{g} / \mathrm{mL})$ and valproic acid (10 mM) (both Sigma).

\section{Immunochemistry}

Protocol and primary antibodies are described in Supplementary Materials and Methods. Analysis was performed using a Leica DMRBE microscope with Axiocam software.

\section{DNA methylation analysis}

DNA was extracted using a QIAamp DNA mini kit (Qiagen). DNA was bisulfite-converted using an EZ DNA Methylation-Gold kit (Zymo). Bisulfite-converted DNA was processed and quantified using Infinium HumanMethylation450 BeadChips (Illumina) and an iScan system (Illumina). Methylation data analysis was conducted in R software ( $\mathrm{R}$ Core Team) using the chip analysis methylation pipeline (ChAMP; Bioconductor) [18,19]. All data underwent basic quality control and filtering before analysis as part of the CHAMP pipeline. Data were normalized using the beta-mixture quantile correction [20]. Differentially methylated probe (DMP) analysis was conducted using ChAMP. Multiple comparisons were corrected using the Benjamini-Hochberg false discovery rate correction (0.001). Gene enrichment analysis was conducted using DMP analysis outputs. DMPs were filtered to include only those with a $\Delta \beta$ value difference between groups of $\geq 0.5$. The remaining DMPs were sorted by direction of methylation. Associated genes were compiled using the RefSeq library. These gene lists were analyzed for significant terms in the Allen Brain Atlas upregulated gene library using Enrichr [21,22].

\section{Polymerase chain reaction and quantitative polymerase chain reaction}

Protocol and primer sequences are described in Supplementary Materials and Methods. For statistical analysis, independent $t$-tests were conducted using SPSS 25.0 for each gene analyzed. Data are presented as mean \pm standard error of the mean of biological triplicates.

\section{Electrophysiology}

For electrophysiology, recordings and analyses were performed as previously described. Human WGE iPSC STR cells were differentiated using the protocol described above, but K/O and N2B27 media were replaced with the previously described media [23].

\section{Transplantation}

Transplants were conducted as previously described [24]. Briefly, 500,000 cells were transplanted unilaterally into the quinolinic acidlesioned striatum, and rats received immunosuppression using cyclosporin A (10mg/kg, Sandoz). After 7 weeks, rats were perfused transcardially and the brains collected.

\section{Results}

Induced PSCs can be generated from hWGE tissues

To generate iPSCs, hWGE cells were harvested from four separate human fetal samples (see supplementary Figure 1) and transfected with the piggyBac transposon gene delivery vector system containing the reprogramming genes OCT4, SOX2, KLF4, C-MYC and LIN28. This resulted in the generation of multiple iPSC colonies from each hWGE sample, and a single clone from each hWGE-derived iPSC population 
(hWGE iPSC) was then cultured and assessed for pluripotency. All lines exhibited similar cell and colony morphology to hESC controls and were composed of small rounded cells with a high nucleus to cytoplasm ratio (Figure 1A). Pluripotent gene expression was demonstrated across numerous passages in all four lines using RNA analysis (Figure 1B) and immunocytochemistry staining (Figure 1C). Functional pluripotency was demonstrated by derivation of all three germ layers in vitro following spontaneous differentiation (Figure 1D) and in vivo by teratoma formation in immune-deficient hosts (Figure 1E). Collectively, these data demonstrate successful reprogramming of cells harvested from primary hWGE to a pluripotent state.

\section{Human WGE iPSCs and hESCS can differentiate toward an STR fate but retain distinct methylation profiles}

Using established principles of STR differentiation, we tested the capacity of hWGE iPSCs to differentiate toward an STR phenotype and included hESCs as a control. Successful fate specification was confirmed using immunocytochemistry staining (Figure 2A; also see supplementary Figure 2). In brief, dual SMAD inhibition led to the formation of rosette structures typical of neuroectodermal progenitors, identifiable by their flower-like morphology, and expression of ZO-1 at the luminal site and Nestin (NES) in the cytoplasm. Commitment to a neuronal fate was confirmed by expression of $\beta$-III tubulin (TUBB3) and MAP2. Patterning toward a ventral telencephalon progenitor fate was initiated using $S H H$ and DKK1 and confirmed by expression of $D L X 1$ and $D L X 2$. Commitment to an MSN progenitor fate was induced through exposure to Activin A. STR progenitor fate commitment was confirmed by expression of ISL1, GSX2 and FOXP1. Following maturation, MSNs were identified by positive co-expression of critical MSN markers CTIP2 (BCL11B) and DARPP-32.

We then explored differences in CPG DNA methylation between hWGE iPSCs and hESCs both at a pluripotent stage and following subsequent STR differentiation. Differences in CpG methylation were seen between hWGE iPSCs and hESCs, with more extensive hypomethylation in hWGE iPSCs (Figure 2B). Following STR differentiation, both cell types exhibited demethylation changes in similar regions, although the previously observed methylation differences between PSC sources remained largely unchanged (Figure 2B). When compiled into a multidimensional scaling plot, these differences separated samples into four distinct groups: pluripotent hWGE iPSCs, pluripotent hESCs, STR-differentiated hWGE iPSCs and STR-differentiated hESCs (Figure 2C). Thus, following exposure to an STR differentiation protocol, despite obvious sustained methylation differences, both hWGE iPSCs and hESCs acquired similar demethylation changes. A subset of these changes were revealed by gene enrichment analysis to be significantly associated with terms related to the striatum and its substructures (Figure 2D). Collectively, this demonstrates that hWGE iPSCs respond similarly to key STR differentiation cues previously applied to hESCs and exhibit a similar capacity for STR differentiation, yet there remain epigenetic differences between these cell sources.

\section{STR-differentiated hWGE iPSCs share characteristics with hWGE}

We next sought to compare hWGE iPSCs following STR differentiation (hWGE iPSC STR) with cells derived from hWGE (authentic STR cells). RNA analysis (Figure 3A) revealed similar levels of pan-neuronal marker MAP2 $\left(t_{9}=-1.173, P=0.105\right)$, suggesting similar neuronal composition. Between the two cell types there was no significant difference in FOXP1 expression $\left(t_{9}=0.145, P=0.398\right)$. However, hWGE iPSC STR cells expressed greater levels of FOXP2 $\left(t_{9}=-3.567\right.$, $P=0.006)$ and DARPP-32 $\left(\mathrm{t}_{9}=-2.473, P=0.035\right)$, whereas hWGE expressed greater levels of GAD65/67 $\left(\mathrm{t}_{9}=4.173, P=0.002\right)$. GSX2, $D L X 2$ and NKX2-1 are known to be upregulated in the ventral telencephalon, but their expression is reduced in mature MSNs. All three were expressed at significantly lower levels in the hWGE iPSC STR cells (GSX2 $\mathrm{t}_{9}=7.662, P<0.001 ; D L X 2 \mathrm{t}_{9}=9.307, P<0.001 ; N K X 2-1$ $\left.\mathrm{t}_{9}=3.743, P=0.005\right)$, implying maturation of these cells.

We also explored potential functional differences between these cell types using patch clamp electrophysiological analysis at early (21-30 days) and late (42-45 days) time points (Figure 3B; also see supplementary Table 3 ). A higher percentage of hWGE iPSC STR cells displayed induced action potentials (APs) compared with hWGE (hWGE iPSC STR, early $89 \%$, late $100 \%$; hWGE, early $70 \%$, late $40 \%$ ), and the amplitude of induced APs was higher in hWGE iPSC STR cells than in hWGE. A single spontaneous AP was seen in hWGE iPSC STR cells, but none was seen in hWGE. The output values for the resting membrane potential evaluations (typically in the range of $-50 \mathrm{mV}$ to $-70 \mathrm{mV}$ in more mature neurons) indicated low levels of maturity in all neurons (hWGE iPSC STR, early $-35.4 \pm 3.6 \mathrm{mV}$, late $-28.6 \pm 2.4$ $\mathrm{mV}$; hWGE, early $-33.9 \pm 5.3 \mathrm{mV}$, late $-37.3 \pm 4.9 \mathrm{mV}$; all values mean \pm standard error of the mean). Thus, the electrophysiological analysis suggested overall neuronal immaturity, although this was less marked in the hWGE iPSC STR cells.

Finally, either hWGE iPSC STR cells or hWGE was transplanted into the lesioned rat striatum, and grafts were collected 7 weeks post-transplantation for immunohistochemical analysis. Graft survival and volume were analyzed using human nuclear antigen, a human-specific marker (Figure 3C). No significant differences in volume were found in grafts derived from either hWGE iPSC STR cells or hWGE $\left(P=\mathrm{t}_{15}=2.95, P=0.086\right)$ (Figure 3D). However, a significantly higher proportion of the grafted hWGE iPSC STR cells were positive for the MSN marker DARPP-32 (human-specific) ( $\mathrm{t}_{15}=33.75, P<$ 0.001) (Figure 3D). Subsequently, hWGE iPSC STR-derived grafts appeared to have yielded a greater number of mature MSNs per unit volume than hWGE-derived grafts.

\section{Discussion}

There is a need to find alternative donor cell sources (most likely PSCs) for future application of CRT for HD. It is known that iPSCs retain some epigenetic features of their tissue of origin and that this can enhance differentiation of fates associated with the tissue of origin $[8,9]$. Thus, iPSCs derived from hWGE could harness their residual epigenome to enhance STR fate differentiation. Here we take the essential first steps to explore this potential donor source.

We have demonstrated the first successful generation of iPSC lines from four separate hWGE tissues and validated their pluripotency. Using developmental principles previously applied to hESCs for STR differentiation [25-27], we found that these hWGE iPSCs differentiate into neurons expressing a range of MSN markers, including FOXP1, CTIP2 and DARPP-32, similar to what is achievable with hESCs. We also examined the methylome of hWGE iPSCs and hESCs exposed to the STR differentiation protocol and demonstrated significant demethylation at $\mathrm{CpG}$ sites associated with STR genes in both, consistent with the current understanding of the developmental role of methylation [28]. However, although hWGE iPSCs and hESCs appeared to have differentiated into equivalent STR phenotypes in terms of selected STR markers and the demethylation of STR genes, obvious methylome differences persisted. As mentioned, it has been established that iPSCs can retain an epigenetic memory of their tissue of origin, which enhances their capacity to differentiate toward cell fates associated with that original tissue. Human WGE iPSCs may benefit from an epigenetic memory retained from their STR origin, and this epigenetic background may allow such cells to be more suitable for STR differentiations than hESCs. However, elucidating the functional consequences of the retained methylome differences observed here, or even how the observed demethylation of STR genes compares with that of normal development, will need to be accomplished in future work by directly comparing hWGE iPSC lines with human iPSCs derived from non-STR tissues, hESCs and hWGE tissues. 

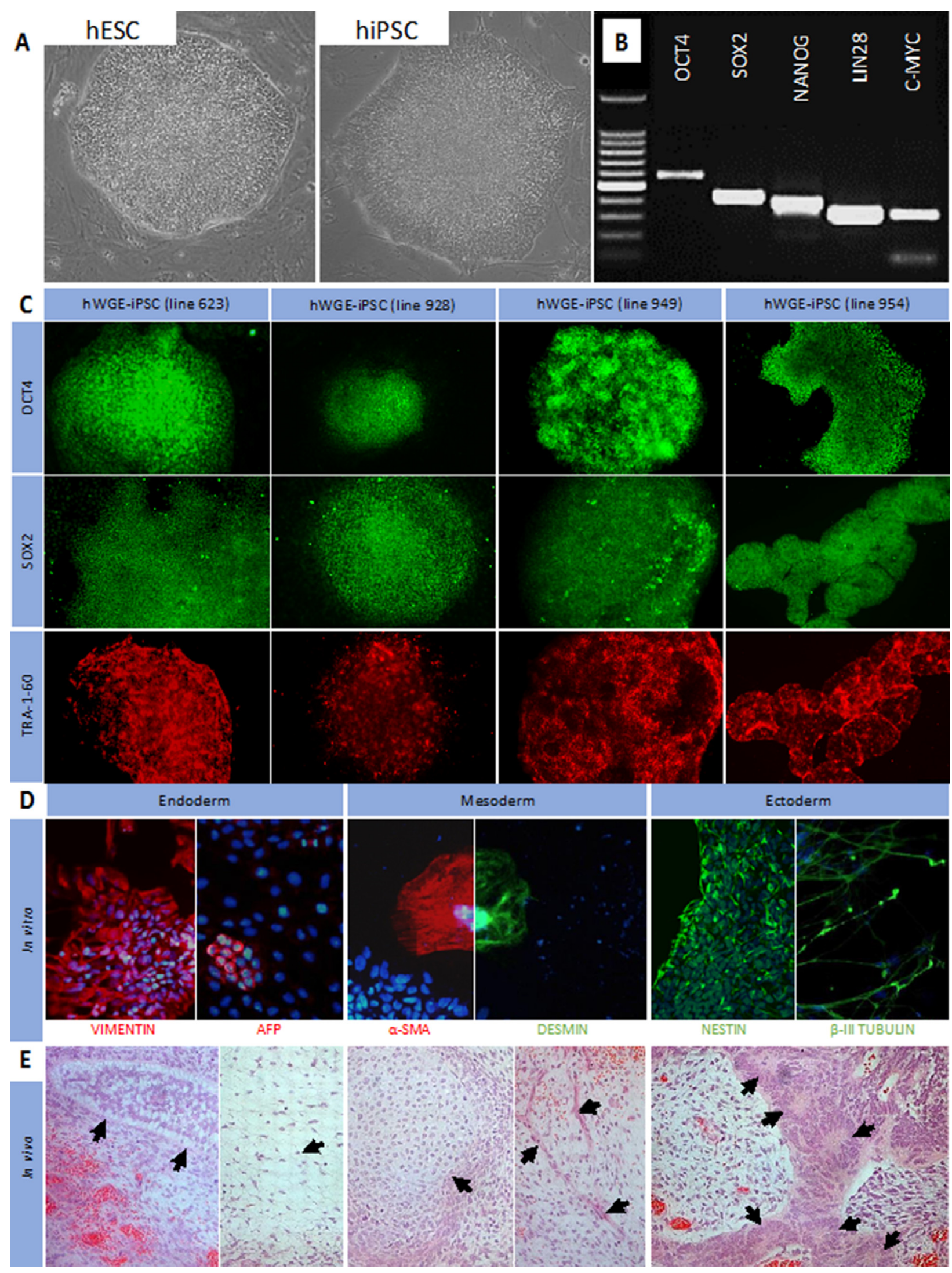

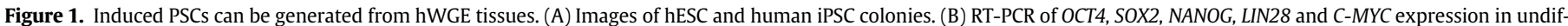

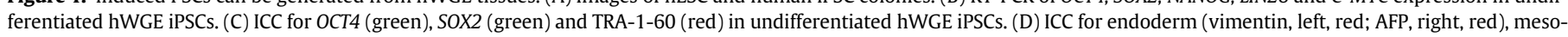

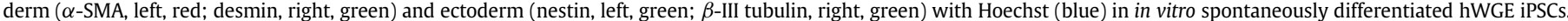

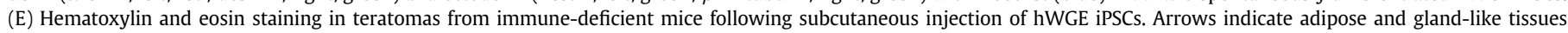

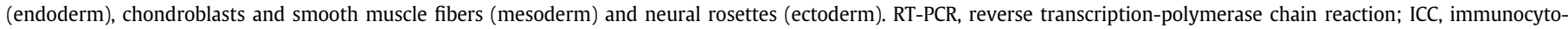
chemistry staining; AFP, alpha fetoprotein; SMA, smooth muscle actin. (Color version of figure is available online). 

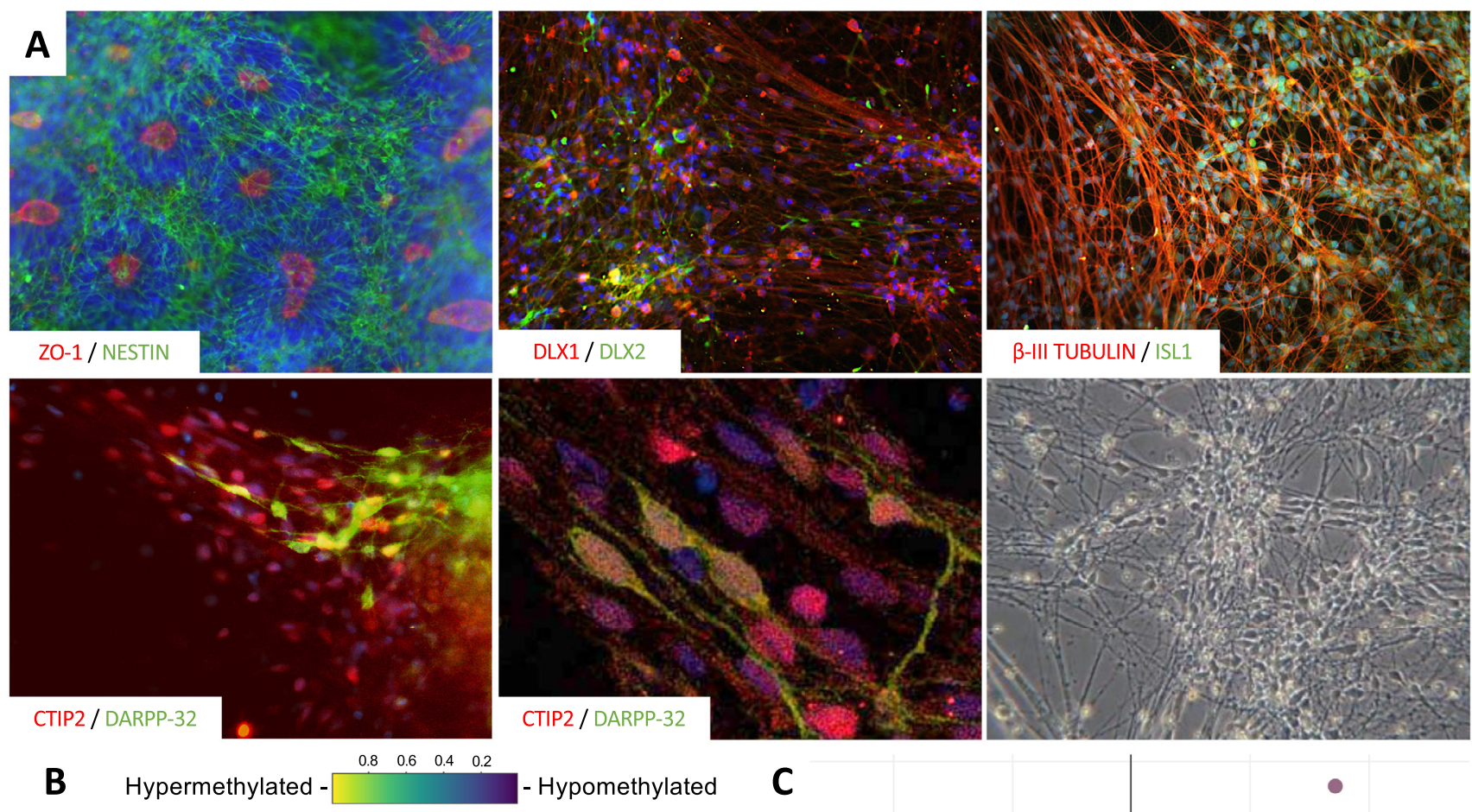

\section{- Hypomethylated}
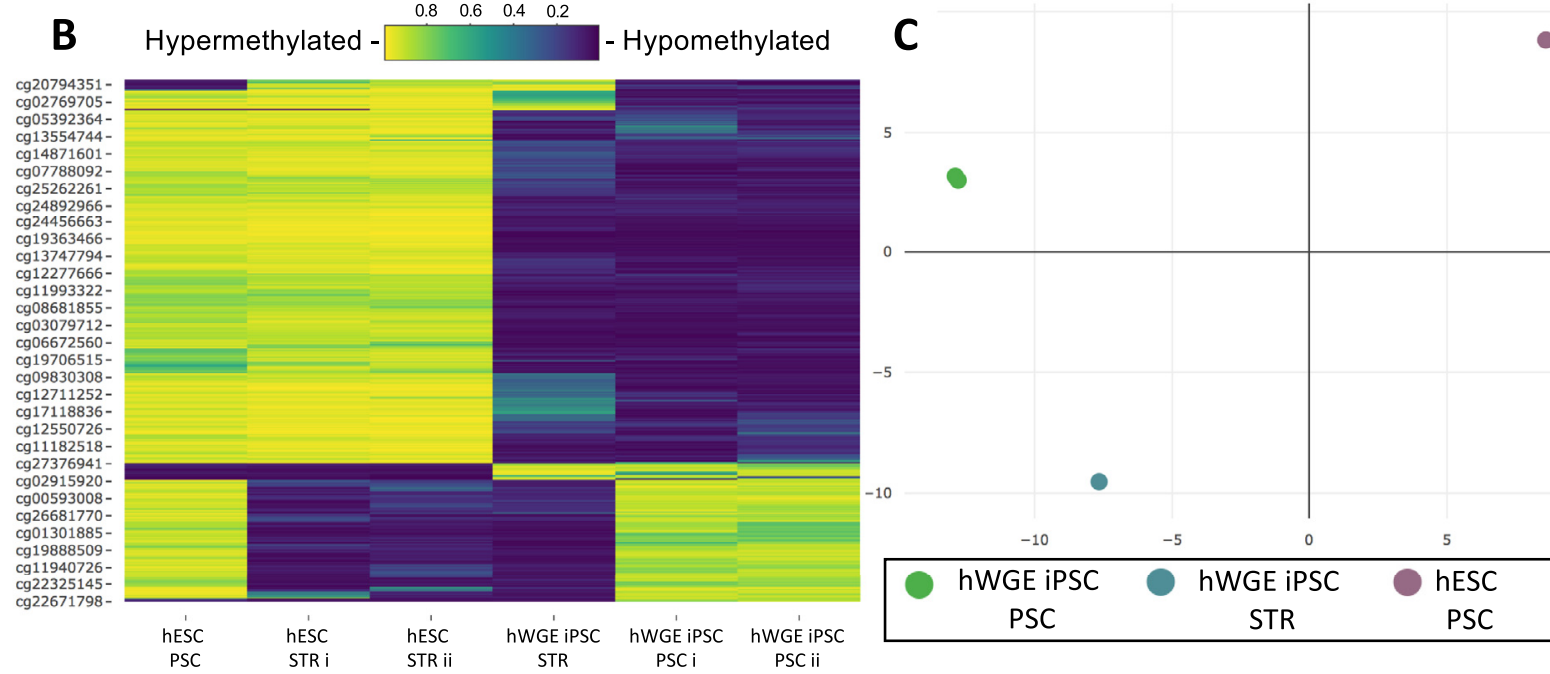

D

\begin{tabular}{|l|l|l|}
\hline Term & Adjusted P-value & \multicolumn{1}{l}{ Associated Genes } \\
\hline Striatum & $1.22 E-06$ & $\begin{array}{l}\text { FAM49A; SEMA5B; DOCK4; GPR88; SLC41A1; SLC4A4; CACNA1H; THBS4; ADCY5; PIK3C2B; DOCK1O; ALCAM; SIPA1L1; CCND2; } \\
\text { ATXN1; ABLIM2; CHST11; GRK5; GNG7; CTNNA1; OTOF; PMEPA1; RGS20; ZSWIM6; PHACTR1; DLGAP2; RGS9; CA12; KCNJ4; PRKCH; } \\
\text { BCL11B; TESC; LMO2; BAIAP2; MEIS2; PDE7B }\end{array}$ \\
\hline Caudoputamen & $8.07 E-06$ & $\begin{array}{l}\text { SEMA5B; DOCK4; GPR88; SLC41A1; ECE1; SLC4A4; CACNA1H; THBS4; ADCY5; PIK3C2B; CCND2; ABLIM2; CHST11; GNG7; ATOH8; } \\
\text { CTNNA1; OTOF; PMEPA1; RGS20; ZSWIM6; PHACTR1; RGS9; CA12; KCNJ4; PRKCH; MBNL2; BCL11B; TESC; LMO2; BAIAP2; SORCS2; } \\
\text { MEIS2; CACNB2; PDE7B }\end{array}$ \\
\hline $\begin{array}{l}\text { Striatum dorsal } \\
\text { region }\end{array}$ & $5.38 E-06$ & $\begin{array}{l}\text { SEMA5B; DOCK4; GPR88; SLC41A1; ECE1; SLC4A4; CACNA1H; THBS4; ADCY5; PIK3C2B; CCND2; ABLIM2; CHST11; GNG7; ATOH8; } \\
\text { CTNNA1; OTOF; PMEPA1; RGS20; ZSWIM6; PHACTR1; RGS9; CA12; KCNJ4; PRKCH; MBNL2; BCL11B; TESC; LMO2; BAIAP2; SORCS2; } \\
\text { MEIS2; CACNB2; PDE7B }\end{array}$ \\
\hline $\begin{array}{l}\text { Striatum ventral } \\
\text { region }\end{array}$ & $4.03 E-06$ & $\begin{array}{l}\text { FAM49A; SEMA5B; GPR88; SLC41A1; HTR2A; SLC4A4; SLC1A7; CACNA1H; ADCY5; PIK3C2B; DOCK10; ALCAM; SIPA1L1; ABLIM2; } \\
\text { TRPS1; GNG7; PDE4B; OOOF; RGS20; ZSWIM6; PHACTR1; RGS9; TBC1D16; CA12; KCNJ4; PRKCH; BCL11B; TESC; BAIAP2; GABRG3; } \\
\text { MEIS2; ADAM12; HHIPL1; PDE7B }\end{array}$ \\
\hline
\end{tabular}

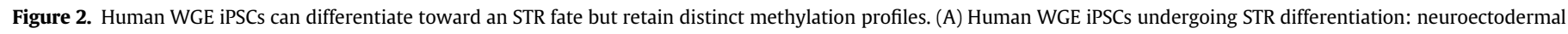

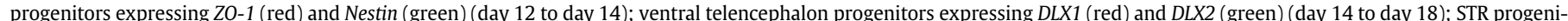

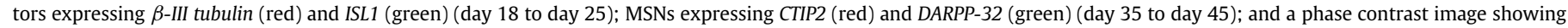

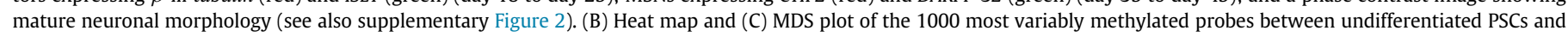

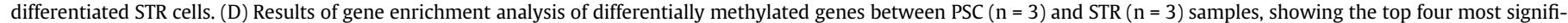

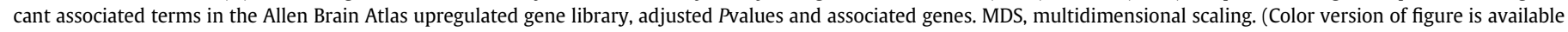
online). 

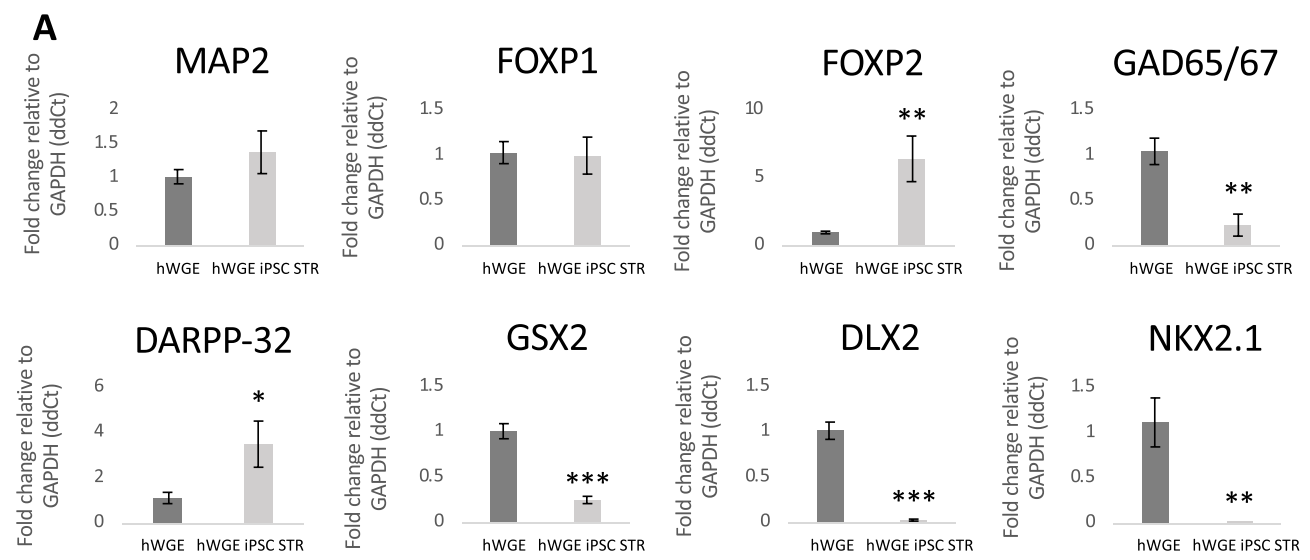

\begin{tabular}{|l|l|l|l|l|l|}
\hline B Cells & Capacitance & $\begin{array}{c}\text { Resting membrane } \\
\text { potential }\end{array}$ & $\begin{array}{c}\text { Amplitude of } \\
\text { induced AP }\end{array}$ & $\begin{array}{c}\text { Max Na+ current } \\
\text { density }\end{array}$ & $\begin{array}{c}\text { Max K+ current } \\
\text { density }\end{array}$ \\
\hline $\begin{array}{l}\text { hWGE iPSC } \\
\text { STRs (early) }\end{array}$ & $11.2+/-1.4 \mathrm{pF}$ & $-35.4+/-3.6 \mathrm{mV}$ & $18.5+/-5.3 \mathrm{mV}$ & $-66.7+/-23.8 \mathrm{pA} / \mathrm{pF}$ & $90.1+/-12.0 \mathrm{pA} / \mathrm{pF}$ \\
\hline $\begin{array}{l}\text { hWGE iPS - } \\
\text { STRs (late) }\end{array}$ & $13.0+/-3.6 \mathrm{pF}$ & $-28.6+/-2.4 \mathrm{mV}$ & $37.1+/-5.5 \mathrm{mV}$ & $-197.3+/-35.5 \mathrm{pA} / \mathrm{pF}$ & $190.6+/-40.9 \mathrm{pA} / \mathrm{pF}$ \\
\hline $\begin{array}{l}\text { hWGE } \\
\text { (early) }\end{array}$ & $6.4+/-1.3 \mathrm{pF}$ & $-33.9+/-5.3 \mathrm{mV}$ & $7.8+/-1.4 \mathrm{mV}$ & $-11.7+/-2.7 \mathrm{pA} / \mathrm{pF}$ & $50.2+/-10.7 \mathrm{pA} / \mathrm{pF}$ \\
\hline $\begin{array}{l}\text { hWGE } \\
\text { (late) }\end{array}$ & $5.9+/-0.9 \mathrm{pF}$ & $-37.3+/-4.9 \mathrm{mV}$ & $10.3+/-2.3 \mathrm{mV}$ & $-18.6+/-5.0 \mathrm{pA} / \mathrm{pF}$ & $49.9+/-16.5 \mathrm{pA} / \mathrm{pF}$ \\
\hline
\end{tabular}
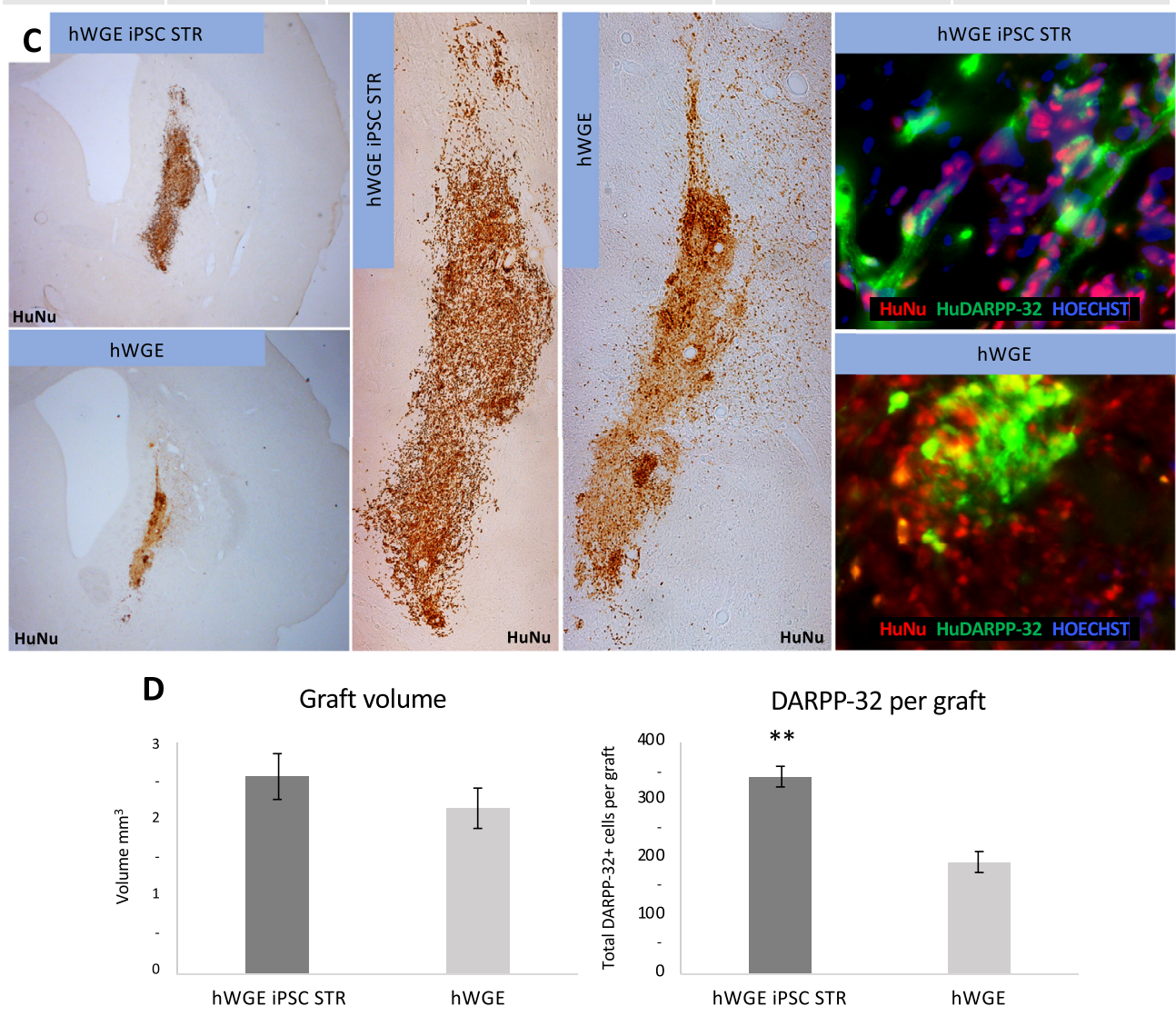

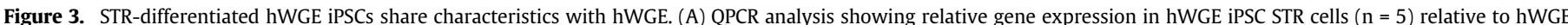

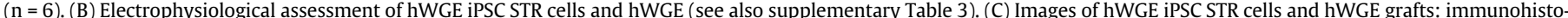

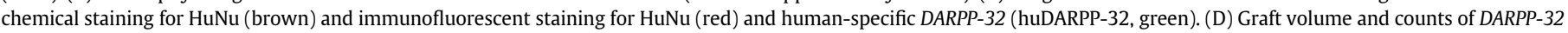
cells per graft. ${ }^{*} P<0.05,{ }^{* *} P<0.01,{ }^{* * *} P<0.001$. HuNu, human nuclear antigen; QPCR, quantitative polymerase chain reaction. (Color version of figure is available online). 
We next compared hWGE iPSC STR cells with an authentic source of MSNs: hWGE. Gene expression analysis of in vitro cultures suggested that hWGE iPSC STR cells were overall more mature than their hWGE counterparts. Specifically, despite similar levels of MAP2 and FOXP1 expression, we found significantly higher DARPP-32 expression in the hWGE iPSC STR cells. Conversely, significantly higher expression of earlier ventral telencephalic markers GSX2, DLX2 and NKX2-1 were observed in hWGE samples. Electrophysiological analysis corroborated these findings. Human WGE iPSC STR cells exhibited a greater number of APs and at higher amplitudes than the hWGEderived cells, although in all cases the amplitudes were lower than anticipated in fully mature neurons.

Following intra-STR transplantation into an HD model, we observed significantly greater numbers of DARPP-32-expressing cells in hWGE iPSC STR grafts compared with hWGE grafts, despite graft volumes being similar. We cannot comment on the functionality of these grafts, although we can confirm the readiness of hWGE iPSCs to differentiate into MSNs in vivo. There are a number of potential explanations as to why these grafts appear to be enriched for DARPP32-positive cells compared with hWGE. For example, STR differentiation is designed to produce MSN progenitors, rather than a full complement of hWGE cells (e.g., STR interneurons), which is consistent with the higher expression of GAD65/67 (expressed by both MSNs and STR interneurons) observed in hWGE. Alternatively, these differences could result from the variances in maturity suggested by our in vitro data, and further in vivo graft maturation could perhaps alleviate these differences.

In summary, although hWGE iPSCs appear to possess an STR differentiation capacity similar to that of hESCs, their methylation profiles remain distinct. It is possible that these differences represent an epigenetic memory of tissue of origin, which could enable hWGE iPSCs to produce MSNs that are more similar to their original tissue: hWGE. We have established that hWGE iPSCs produce MSNs that share fundamental characteristics with hWGE-derived MSNs, thus confirming their potential as a useful alternative cell source for CRT for HD and offering evidence that such cell lines may be capable of overcoming the limitations of fetal tissues.

\section{Declaration of Competing Interest}

The authors have no commercial, proprietary or financial interest in the products or companies described in this article.

\section{Funding}

This work was funded using a Thailand Graduate Institute of Science and Technology PhD studentship, a Naresuan University postdoctoral grant and a Wellcome Trust ISSF seed corn grant. It was partially funded by a Wellcome Trust PhD studentship as well as MRC project 500971 and Repair-HD (EU FP7, 504870).

\section{Author Contributions}

Conception and design of the study: NC, CMK and AER. Acquisition of data: NC, OJMB, NNV, CS, AG, VHR and SVP. Analysis and interpretation of data: NC, OJMB, NNV, CS, AG, VHR and SVP. Drafting or revising the manuscript: OJMB, SVP, CMK and AER. All authors have approved the final article.

\section{Acknowledgments}

The authors thank Lesley Bates and Dr Susan Hunter for their technical assistance.

\section{Supplementary materials}

Supplementary material associated with this article can be found in the online version at doi:10.1016/j.jcyt.2020.06.001.

\section{References}

[1] Bates G, Tabrizi S, Jones L. Huntington's disease (No. 64). UK: Oxford University Press; 2014.

[2] Rosas HD, Tuch DS, Hevelone ND, Zaleta AK, Vangel M, Hersch SM, Salat DH. Diffusion tensor imaging in presymptomatic and early Huntington's disease: selective white matter pathology and its relationship to clinical measures. Mov Disord 2006:21:1317-25

[3] Tabrizi SJ, Scahill RI, Durr A, Roos RA, Leavitt BR, Jones R, Landwehrmeyer GB, Fox NC, Johnson H, Hicks SL, et al. Biological and clinical changes in premanifest and early stage Huntington's disease in the TRACK-HD study: the 12-month longitudinal analysis. Lancet Neurol 2011:10:31-42.

[4] Precious SV, Kelly CM. Transplantation in HD: are we transplanting the right cells? In: Tunalı NE, ed. Huntington's disease: molecular pathogenesis and current models, London, UK: IntechOpen Ltd; 2017. p. 119.

[5] Barker RA, Mason SL, Harrower TP, Swain RA, Ho AK, Sahakian BJ, Mathur R, Elneil S, Thornton S, Hurrelbrink C, et al. The long-term safety and efficacy of bilateral transplantation of human fetal striatal tissue in patients with mild to moderate Huntington's disease. J Neurol Neurosurg Psychiatry 2013;84:657-65.

[6] Rosser AE, Bachoud-Lévi AC. Clinical trials of neural transplantation in Huntington's disease. In: Dunnett S, Bjorkland A, eds. Functional Neural Transplantation III, Primary and Stem Cell Therapies for Brain Repair, Part I, Waxman SG, Stein DG, Swaab DF, Fields HL, eds. Progress in brain research, 200, Oxford, UK: Elsevier; 2012:345-71

[7] Precious SV, Zietlow R, Dunnett SB, Kelly CM, Rosser AE. Is there a place for human fetal-derived stem cells for cell replacement therapy in Huntington's disease? Neurochem Int 2017;106:114-21

[8] Kim K, Doi A, Wen B, Ng K, Zhao R, Cahan P, Kim J, Aryee MJ, Ji H, Ehrlich LIR, et al. Epigenetic memory in induced pluripotent stem cells. Nature 2010:467:285-90.

[9] Polo JM, Liu S, Figueroa ME, Kulalert W, Eminli S, Tan KY, Apostolou E, Stadtfeld M, Li Y, Shioda T, et al. Cell type of origin influences the molecular and functional properties of mouse induced pluripotent stem cells. Nat Biotechnol 2010;28:848.

[10] Bar-Nur O, Russ HA, Efrat S, Benvenisty N. Epigenetic memory and preferential lineage-specific differentiation in induced pluripotent stem cells derived from human pancreatic islet beta cells. Cell Stem cell 2011;9:17-23.

[11] Pfaff N, Lachmann N, Kohlscheen S, Sgodda M, Araúzo-Bravo MJ, Greber B, Kues W, Glage S, Baum C, Niemann H, et al. Efficient hematopoietic redifferentiation of induced pluripotent stem cells derived from primitive murine bone marrow cells. Stem Cells Dev 2012;21:689-701.

[12] Xu H, Yi BA, Wu H, Bock C, Gu H, Lui KO, Park JHC, Shao Y, Riley AK, Domian IJ et al. Highly efficient derivation of ventricular cardiomyocytes from induced pluripotent stem cells with a distinct epigenetic signature. Cell Res 2012; $22: 142-54$

[13] Hiler D, Chen X, Hazen J, Kupriyanov S, Carroll PA, Qu C, Xu B, Johnson D, Griffiths L, Frase S, et al. Quantification of retinogenesis in 3D cultures reveals epigenetic memory and higher efficiency in iPSCs derived from rod photoreceptors. Cell Stem cell 2015:17:101-15.

[14] Roost MS, Slieker RC, Bialecka M, Van Iperen L, Fernandes MMG, He N, Suchiman HED, Szuhai K, Carlotti F, De Koning EJ, et al. DNA methylation and transcriptional trajectories during human development and reprogramming of isogenic pluripotent stem cells. Nat Commun 2017;8:1-11.

[15] Hargus G, Ehrlich M, Araúzo-Bravo MJ, Hemmer K, Hallmann AL, Reinhardt P, Kim KP, Adachi K, Santourlidis S, Ghanjati F, et al. Origin-dependent neural cell identities in differentiated human iPSCs in vitro and after transplantation into the mouse brain. Cell Rep 2014;8:1697-703.

[16] Roberton VH, Rosser AE, McGorrian AM, Precious SV. Dissection and preparation of human primary fetal ganglionic eminence tissue for research and clinical applications. In: Precious S, Rosser A, Dunnett S, eds. Huntington's disease, NY, New York: Humana Press; 2018:573-83.

[17] Yusa K, Rad R, Takeda J, Bradley A. Generation of transgene-free induced pluripotent mouse stem cells by the piggyBac transposon. Nat Methods 2009;6:363.

[18] Aryee MJ, Jaffe AE, Corrada-Bravo H, Ladd-Acosta C, Feinberg AP, Hansen KD, Irizarry RA. Minfi: a flexible and comprehensive Bioconductor package for the analysis of Infinium DNA methylation microarrays. Bioinformatics 2014;30:1363-9.

[19] Morris TJ, Butcher LM, Feber A, Teschendorff AE, Chakravarthy AR, Wojdacz TK, Beck S. ChAMP: 450k chip analysis methylation pipeline. Bioinformatics 2014;30:428-30.

[20] Teschendorff AE, Marabita F, Lechner M, Bartlett T, Tegner J, Gomez-Cabrero D, Beck S. A beta-mixture quantile normalization method for correcting probe design bias in Illumina Infinium 450k DNA methylation data. Bioinformatics 2013;29:189-96.

[21] Chen EY, Tan CM, Kou Y, Duan Q, Wang Z, Meirelles GV, Clark NR, Ma'ayan A Enrichr: interactive and collaborative HTML5 gene list enrichment analysis tool. BMC Bioinformatics 2013; 14:128.

[22] Kuleshov MV, Jones MR, Rouillard AD, Fernandez NF, Duan Q Wang Z, Koplev S, Jenkins SL, Jagodnik KM, Lachmann A, et al. Enrichr: a comprehensive gene set enrichment analysis web server 2016 update. Nucleic Acids Res 2016;44:90-7.

[23] Telezhkin V, Schnell C, Yarova P, Yung S, Cope E, Hughes A, Thompson BA Sanders P, Geater C, Hancock JM, et al. Forced cell cycle exit and modulation 
of GABAA, CREB, and GSK3 $\beta$ signaling promote functional maturation of induced pluripotent stem cell-derived neurons. Am J Physiol Cell Physiol 2016;310:520-41.

[24] Lelos MJ, Roberton VH, Vinh NN, Harrison C, Eriksen P, Torres EM, Clinch SP, Rosser AE, Dunnett SB. Direct comparison of rat-and human-derived ganglionic eminence tissue grafts on motor function. Cell Transplant 2016;25:665-75.

[25] Arber C, Precious SV, Cambray S, Risner-Janiczek JR, Kelly C, Noakes Z, Fjodorova M, Heuer A, Ungless MA, Rodríguez TA, et al. Activin A directs striatal projection neuron differentiation of human pluripotent stem cells. Development 2015;142:1375-86.
[26] Aubry L, Bugi A, Lefort N, Rousseau F, Peschanski M, Perrier AL. Striatal progenitors derived from human ES cells mature into DARPP32 neurons in vitro and in quinolinic acid-lesioned rats. Proc Natl Acad Sci U S A 2008;105:16707-12.

[27] Nicoleau C, Varela C, Bonnefond C, Maury Y, Bugi A, Aubry L, Viegas P, Bourgois-Rocha F, Peschanski M, Perrier AL. Embryonic stem cells neural differentiation qualifies the role of Wnt $/ \beta$-Catenin signals in human telencephalic specification and regionalization. Stem Cells 2013;31:1763-74.

[28] Cedar H, Bergman Y. Programming of DNA methylation patterns. Annu Rev Biochem 2012;81:97-117. 